\title{
Apnoea and bradycardia during epileptic seizures: relation to sudden death in epilepsy
}

\author{
L Nashef, F Walker, P Allen, J W A S Sander, S D Shorvon, D R Fish
}

\begin{abstract}
Objective-To record non-invasively ictal cardiorespiratory variables.

Methods-Techniques employed in polysomnography were used in patients with epilepsy undergoing EEG-video recording at a telemetry unit.

Results-Apnoea ( $>10$, range $>10-63$, mean $24 \mathrm{~s}$ ) was seen in 20 of 47 clinical seizures (three secondary generalised, 16 complex partial, and one tonic) and 10 of 17 patients. Apnoea was central in 10 patients, but obstructive apnoea was also recorded in three of 10 . Oxyhaemoglobin saturation $\left(\mathrm{Spo}_{2}\right)$ dropped to less than $85 \%$ in 10 seizures (six patients). An increase in heart rate was common $(91 \%$ of seizures). Bradycardia/sinus arrest was documented in four patients (mean maximum $R R$ interval $5 \cdot 36$, range $2 \cdot 8-8 \cdot 6 \mathrm{~s}$ ) but always in the context of a change in respiratory pattern.
\end{abstract}

Conclusion-Ictal apnoea was often seen. The occurrence of bradycardia in association with apnoea suggests the involvement of cardiorespiratory reflexes. Similar mechanisms may operate in cases of sudden death in epilepsy.

(F Neurol Neurosurg Psychiatry 1996;60:297-300)

Keywords: ictal apnoea, ictal bradycardia, sudden death in epilepsy

It is well documented that otherwise well patients with epilepsy may die unexpectedly (sudden unexpected death in epilepsy (SUDEP)). ${ }^{1-17}$ Ictal autonomic mechanisms have been postulated with recent attention focused on changes in cardiac rhythm. ${ }^{1618-22}$ Apnoea is known to occur during seizures, ${ }^{1823-27}$ but systematic studies of ictal respiratory changes in adults are few. We set out to assess the yield and feasibility of routinely applying polysomnography techniques to seizure recordings in patients undergoing EEG/videotelemetry. $^{28}$

\section{Patients and methods}

The study, approved by the hospital ethics committee, was performed in the telemetry unit at the National Hospital for Neurology and Neurosurgery. Patients with a probable diagnosis of epilepsy admitted for EEG/videotelemetry were recruited. These were consecutive patients (two excluded) being monitored using an in house assembled system that was adapted for the additional variables.

As well as routine video/audio recording time synchronised with 22 channels of EEG/ECG ( $\pm 5 \mathrm{EMG} / \mathrm{EOG}$ ), the following were recorded: oxygen saturation and plethysmography using a pulse oximeter (Nellcor N200E, normal setting, disposable digital probes, Nellcor Adult Oxisensor D-25), mouth and nasal airflow (disposable Nellcor Adult Airflow Sensor, Model 971), and respiration (chest and abdominal Respitrace bands).

All physiological data, including oximetry, could be simultaneously displayed and epochs reviewed or plotted with an adjustable time scale of 10-40 seconds per page. Seizures were identified by review of video/EEG recordings. Baseline ECG rates were determined for epochs between 10 and 20 seconds and expressed as beats per minute (bpm). Ictal maximum and minimum rates were noted if the minimum rate differed by more than 10 bpm from baseline. The longest $R R$ interval was measured. Respiratory changes associated with seizures were noted: ictal apnoea was defined as cessation of airflow of more than 10 seconds and characterised as central or obstructive.

\section{Results}

Of 33 patients approached, one declined and a further three withdrew. One other patient was being assessed for suspected apnoeic spells distinct from his epileptic seizures. Only the epileptic seizures were analysed. Seventeen patients ( 11 men, six women) had 47 clinical seizures recorded with additional cardiorespiratory variables. Mean age was 32 (range 18-43) years. The indication for recording was presurgical assessment in 13 and diagnostic in four. Only six of 17 patients had small reductions in their antiepileptic drugs. The epilepsy diagnosis was symptomatic generalised in two and localisation related in 15 (10 temporal, two frontal, three location uncertain).

The 47 clinical seizures included three secondary generalised tonic clonic seizures, 35 complex partial seizures, one spontaneous absence, and eight predominantly tonic seizures. Auras or pure electrographic seizures were not analysed.

\section{TECHNICAL CONSIDERATIONS}

The recordings were informative in all but one case. Interpretation relied on integration of all data. Movement may result in an artefactual 


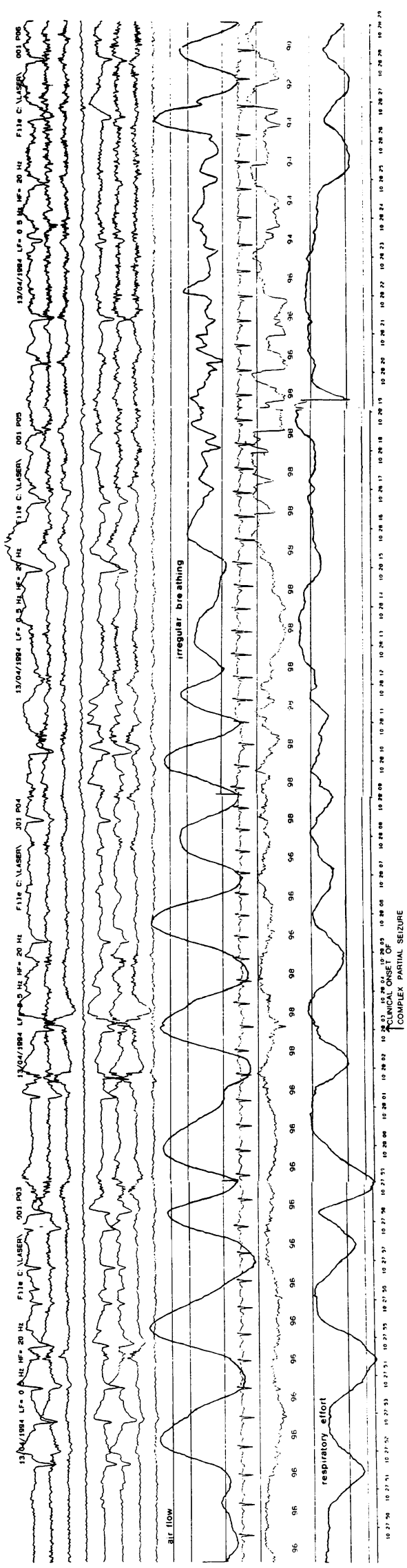

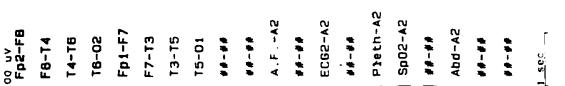

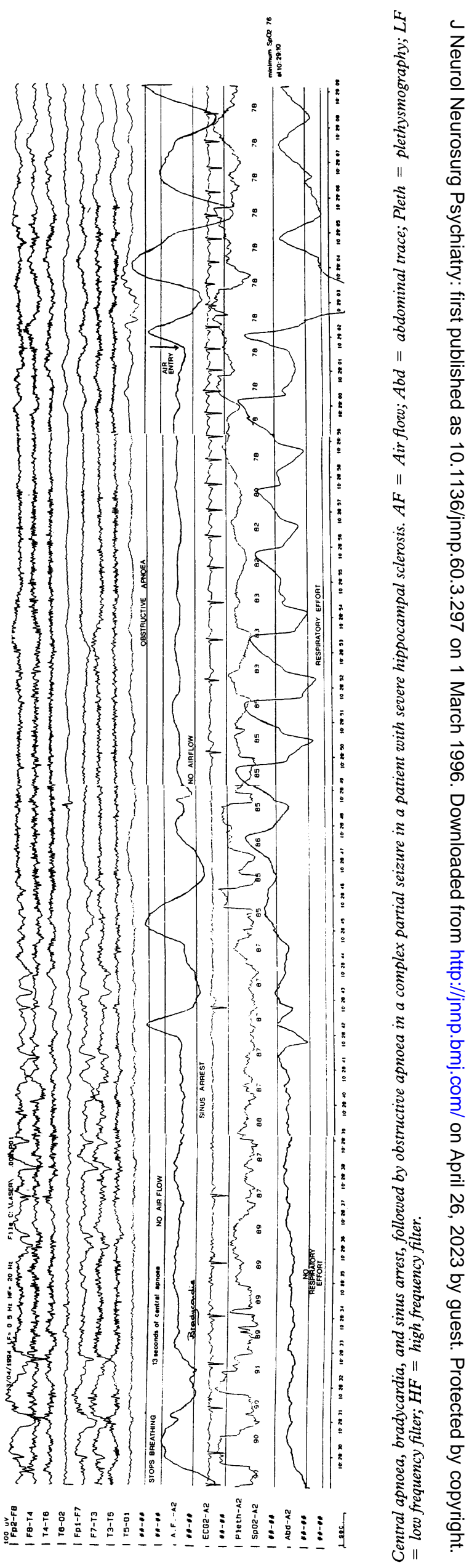


drop in oxyhaemoglobin saturation $\left(\mathrm{SpO}_{2}\right)$ readings towards $85 \%^{29}$ and gross movements in readings cutting out altogether. ${ }^{30}$ Preservation of plethysmography signal, gradual changes consistent with other physiological variables, and an appropriate lag $^{31}$ in relation to occurrence of apnoea were all helpful in assessing validity of $\mathrm{SpO}_{2}$ data. Only $\mathrm{Spo}_{2}$ readings below $85 \%$ and supported by such concordant data are reported here; this probably underestimates ictal changes in oxygen saturation. Regarding other respiratory variables, even when the trace from one channel was unclear, the overall recording was informative in all but one case. The ECG traces were sometimes obscured by muscle artefact (see below). The least tolerated of the additional measurements by the patients was the airflow.

\section{RESPIRATORY CHANGES}

Apnoea associated with seizures

Apnoea ( $>10 \mathrm{~s}$ ) was documented in 10 of 17 patients (20 of 47 seizures) in three of three secondary generalised tonic clonic seizures, one of eight tonic seizures, and 16 of $35 \mathrm{com}$ plex partial seizures. Duration ranged from $>$ 10 to 63 seconds with a mean of 24 seconds. The apnoea was central in all of the 20 seizures (10 patients), and, when it was possible to ascertain, occurred in expiration (14 of 20 seizures, eight of 10 patients). In addition, in three of 10 patients obstructive apnoea followed central apnoea. During one complex partial seizure infrequent and irregular breathing preceded a period of central apnoea (13 s) which was associated with sinus arrest (maximum RR interval $7.3 \mathrm{~s}$; figure). This was followed by obstructive apnoea lasting 14 seconds during which the (seated) patient's head was slumped on to the chest. In two of the three generalised seizures, obstructive apnoea was also seen during the postictal phase.

\section{$\mathrm{SpO}_{2}$ during seizures}

$\mathrm{SpO}_{2}$ dropped to less than $85 \%$ in 10 seizures (six patients) in association with apnoea. The range was $55-83 \%$ (mean 71 ) and these changes were gradual and consistent with other events recorded and appropriate in timing to the occurrence of apnoea. Mean lag from the onset of the apnoeic spell to the start of a consistent decrease in $\mathrm{SpO}_{2}$ from baseline was 25 (range 6-49) seconds (six seizures). Mean lag to the minimum $\mathrm{Spo}_{2}$ recorded was 75 (range 39-108) seconds (seven seizures), and mean lag to the onset of a consistent rise in $\mathrm{SpO}_{2}$ after return of effective ventilation was 23 (range 11-72) seconds (eight seizures). Quantification was not always possible as patients may have inadequate breathing before or after an episode of apnoea.

HEART RATE DURING SEIZURES

Decrease in heart rate

Transient bradycardia/sinus arrest (mean maximum $R R$ interval $5 \cdot 36$, range $2 \cdot 8-8 \cdot 6 \mathrm{~s}$ ) was documented in four patients (minimum five seizures). In three patients this occurred during apnoea. In the fourth patient bradycar- dia occurred soon after seizure at a time of altered respiratory pattern. The patient characteristically emitted a forceful moan, lasting for 18 seconds and interrupted by some 10 very short inspirations. Lowest heart rates measured over 10 second epochs were equivalent to $6-42 \mathrm{bpm}$ with a mean of $27 \mathrm{bpm}$ in five seizures. These changes were brief, lasting less than 25 seconds.

Another patient with a baseline heart rate of $66 \mathrm{bpm}$, had an initial ictal tachycardia (102 bpm) during a period of hyperventilation. This was followed by an apnoeic spell and relative bradycardia $(54 \mathrm{bpm})$ in one of eight tonic seizures.

In seven patients (including the two with tonic clonic seizures) the ECG tracing was obscured sufficiently at critical times during seizures such that transient bradycardia could not be excluded. In two patients bradycardia was recorded in other seizures.

\section{Increase in heart rate during seizures}

Increase in heart rate was frequently seen occurring in $91 \%$ of seizures (39 of 41), including patients with later ictal bradycardia. The increase in heart rate was usually early on in the seizure but could precede, coincide with, or follow scalp EEG or clinical onset and ranged from 15 to $99 \mathrm{bpm}$ above baseline (mean 40). Maximum heart rates recorded ranged from 78 to 162 (mean 114) bpm.

\section{Discussion}

Theories suggested for the mechanism of sudden death in epilepsy have concentrated on autonomic instability during or soon after overt or subclinical seizures including cardiac arrhythmias. Yet, despite occasional case reports, ${ }^{32-34}$ systematic studies ${ }^{18-22}$ focusing on changes in heart rate in isolation have generally failed to support the hypothesis that malignant cardiac arrhythmias commonly occur during seizures. In this study of patients with telemetry, cardiorespiratory changes were often considerable, despite the fact that seizures recorded were mostly complex partial rather than secondarily generalised.

Tachycardias occurred very often, as previously reported. ${ }^{20}$ This is considered a sympathetically mediated consequence of seizure discharge. Apnoea was seen in 10 of 17 patients and bradyarrhythmias in four of 17 . Central apnoea was more common than obstructive apnoea. However, this may have been influenced by the presence of staff.

It is interesting that in a sheep seizure model of epileptic sudden death, striking hypoventilation was seen in the sudden death group but not in the surviving animals. ${ }^{35}$ Some case reports refer to ictal bradycardia/sinus arrest. ${ }^{32-34}$ Interpretation of bradyarrhythmias is incomplete without simultaneous recording of respiration. In this study transient bradycardia/sinus arrest always occurred with a change in respiratory pattern. In three of four patients, bradyarrhythmias were not seen at or soon after the onset of the seizure but occurred later during an apnoeic spell. In the fourth patient, 
this occurred soon after seizure onset, at a time of altered respiration when prolonged forceful moans were interrupted by very brief inspirations.

Regulation of the cardiac and respiratory systems are interrelated. One cardiorespiratory reflex of relevance is that of bradycardia in the presence of apnoea. Daly ${ }^{36}$ has emphasised the risk of cardiac arrest in any clinical situation in which the patient's respiration is depressed either reflexly or centrally, a time of heightened vagal sensitivity. By contrast with the tachycardia seen in the presence of hyperventilation, carotid body stimulation secondary to and in the presence of apnoea results in bradycardia. $^{37}$ In this situation, ictal parasympathetic overactivity, usually overshadowed by sympathetic changes, may acquire greater importance. Although the seizure discharge could theoretically activate central regions, causing both bradycardia and apnoea, the evolution of the bradycardia in relation to the apnoea makes this less likely. Our results suggest that bradyarrhythmias may be potentiated by cardiorespiratory reflexes with apnoea playing a central part, and hypoxia providing an additional contributory factor. Of interest in this regard is the finding that sudden unexpected death in epilepsy is more common in young patients and that the magnitude of cardiorespiratory reflexes is known to diminish with age. ${ }^{38}$

Whether patients consistently shown to have cardiorespiratory changes during seizures are more at risk of sudden death remains speculative. However, the finding of such ictal changes may influence clinical management during presurgical assessment, given an incidence of sudden unexpected death in epilepsy of the order of 1:200 per year in patients with chronic epilepsy. ${ }^{10}$ The potential influence of seizure focus on the type of changes found is of interest and requires a larger study, as does the influence of patient stimulation and positioning on apnoea. The second may be relevant to the finding, as yet unexplained, that most sudden unexpected deaths in epilepsy are unwitnessed.46101213 In the meantime, basic principles relating to both cardiac and respiratory resuscitation in seizures should be highlighted.

We thank Action Research for funding the study on sudden death in epilepsy and the National Society of Epilepsy for its support.

1 Lathers CM, Schraeder PL. Epilepsy and sudden death. New

York: Marcel Dekker, 1990 .
Hirsch CS, Martin DL. Unexpected death in young epileptics. Neurology 1971;21:682-90.

3 Jay GW, Leestma JE. Sudden death in epilepsy. A comprehensive review of the literature and proposed mechanisms. Acta Neurol Scand 1981;63(suppl 82):5-66.

4 Leestma JE, Walczak T, Hughes J, Kalelkar MB, Teas S. A prospective study on sudden unexpected death in epilepsy. Ann Neurol 1989;26:195-203.

5 Brown SW. Sudden death and epilepsy: clinical review. Seizure 1992;1:71-3.

6 Terrence CF, Rao GR, Perper JA. Neurogenic pulmonary edema in unexpected unexplained death of epileptic patients. Ann Neurol 1981;9:458-64.

7 Jallon P, Haton F, Maguin P. Death among epileptics. Advances in Epileptology 1989;17:351-5.

8 Tennis P, Cole TB, Annegers JF, Leestma JE, McNutt M, Rajput A. Cohort study of incidence of sudden unexplained death in persons with seizure disorder treated with antiepileptic drugs in Saskatchewan, Canada. Epilepsia 1995;36;29-36.

9 Dasheiff RM. Sudden unexpected death in epilepsy: series from an epilepsy surgery programme and speculation on the relationship to sudden cardiac death. $\mathcal{F}$ Clin Neurophysiol 1991;8:216-22.

10 Nashef L, Sander JWAS, Fish DR, Shorvon SDS. Incidence of sudden unexpected death in an adult outpatient cohort with epilepsy at a tertiary referral centre. f Neurol Neurosurg Psychiatry 1995;58:462-4.

11 Timmings PL. Sudden unexpected death in epilepsy: local audit. Seizure 1993;2:287-90.

12 Harvey AS, Nolan T, Carlin JB. Community-based study of mortality in children with epilepsy. Epilepsia 1993, 34:597-603

13 Earnest MP, Thomas GE, Randall AE, Kenneth FH. Th sudden unexplained death syndrome in epilepsy. Epilepsia 1992;33:310-6.

14 Lund A, Gormsen $H$. The role of antiepileptics in sudde death in epilepsy. Acta Neurol Scand 1985;72:444-6.

15 Lip GYH, Brodie MJ. Sudden death in epilepsy: an avoidable outcome? F $R$ Soc Med 1992;85;609-11.

16 Schraeder PL, Lathers CM. The relation of paroxysma autonomic dysfunction and epileptogenic activity. In: Lathers CM, Schraeder PL, eds. Epilepsy and sudden death. New York: Marcel Dekker, 1990:121-97.

17 Jallon P. Coeur et Epilepsie. Genève: Thèse d'habilitation pour l'obtention du titre de Privat Docent de la Faculte pour Médicine de Genève, 1991.

18 Johnson LC, Davidoff RA. Autonomic changes durin paroxysmal EEG activity. Electroencephalogr Cli Neurophysiol 1964;17:25-35.

19 Devinsky O, Price BH, Cohen CI. Cardiac manifestation of complex partial seizures. Am f Med 1986;80:195-202. 20 Blumhardt LD, Smith PEM, Owen L. Electrographi accompaniments of temporal lobe epileptic seizures. Lancet 1986;i:1051-55.

21 Keilson MJ, Hauser WA, Magrill JP. Electrocardiographic changes during electrographic seizures. Arch Neurol 1989;46: 1169-70.

22 Nousiainen U, Mervaala, Ylinen A, Uusitupa M, Riekkinen $P$. The importance of the ECG in ambulatory EEG recordings. Arch Neurol 1989;46:1171-4.

23 Coulter DL. Partial seizures with apnoea and bradycardia. Arch Neurol 1984;41:173-4.

24 Nelson DA, Ray CD. Respiratory arrest from seizure discharges in limbic system. Arch Neurol 1968;19:199-207.

25 Singh B, Al Shahwan SA, Al Deeb SM. Partial seizures presenting as life threatening apnea. Epilepsia 1993 34:901-3

26 Chatrian GE, Lettich E, Wilkus RJ, Vallarta J. Polygraphi and clinical observations on tonic-autonomic seizures. In: Broughton RJ, ed. Henri Gastaut and the Marseille School's contribution to the neurosciences. EEG supplement No 35. Amsterdam: Elsevier Biomedical Press, 1982:101-24.

27 Gastaut H, Roger J, Ouahchi S, Timsit M, Broughton R. An electro-clinical study of generalized epileptic seizures of tonic expression. Epilepsia 1963;4:15-44.

28 American Thoracic Society. Indications and standards for cardiopulmonary sleep studies. Rev Respir Dis 1989;139: $559-68$.

29 Pologue JA. Pulse oximetry: technical aspects of machin design. Int Anaesthesiol Clin 1987;25:137-53.

30 Hanning CD, Alexander-Williams JM. Pulse oximetry: practical review. BMF 1995;311:367-70.

31 Kryger MH. Monitoring respiratory and cardiac function. In: Kryger MH, Roth T, Dement WC, eds. Principles and practice of sleep medicine. Philadelphia: WB Saunders, 1989:702-15.

32 Fincham RW, Shivapour E, Leis A, Martins JB. Ictal bradycardia with syncope: a case report. Neurology 1992; 42:2222-3.

33 Joske DJL, Davis MJE. Sino-atrial arrest due to temporal lobe epilepsy. Aus NZ f Med 1991;21:62-4.

34 Katz TL, Tiger M, Harner RN. Epileptic cardiac arrhythmia: sinoatrial arrest in 2 patients. Epilepsia 1983;24:248.

35 Johnston SC, Horn JK, Valente J, Simon RP. The role of hypoventilation in a sheep model of epileptic sudden hypoventilation in a sheep model
death. Ann Neurol 1995;37:531-7.

36 Daly $M$ de $B$. Interaction between respiration and circulation. In: Sherniack NS, Widdicombe JG, eds. Handbook of physiology, the respiratory system II. Bethesda: American Physiology Society, 1985:529-94.

37 Spyer KM. Central nervous control of the cardivascula system. In: Bannister R, Mathias CJ, eds. Autonomic fail ure. 3rd ed.1992:55-77

38 Wieling $W$. Non-invasive continuous recording of heart rate and blood pressure in the evaluation of neurovascula control. In: Bannister R, Mathias CJ, eds. Autonomic failure. 3rd ed.1992:291-311. 